\title{
Teach Beyond Your Reach: \\ An instructor's guide to developing and running successful distance learning classes, workshops, training sessions and more

\author{
Neidorf, R. (2006). Medford, NJ: Information Today Inc.
} (ISBN 0-910965-73-0)
}

\author{
Reviewed by \\ Yavuz AKBULUT \\ Anadolu University, TURKEY
}

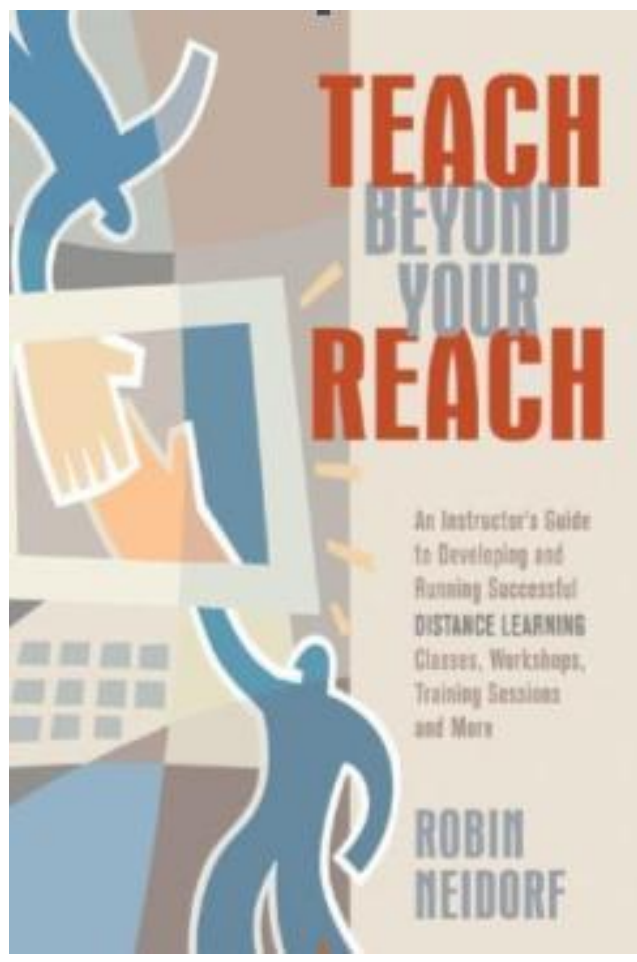

\begin{abstract}
"Teach Beyond Your Reach: An instructor's guide to developing and running successful distance learning classes, workshops, training sessions and more" serves as a guide for novice and experienced distance educators to develop and deliver their own training sessions. The book is consisted of 234 pages ( $+x i)$ covering eight interdependent chapters followed by a useful appendix of further reading resources, sample introductory materials for distance learning and a sample lecture. The author, Robin Neidorf, teaches communications and writing through the online campus of the Univeristy of Phoenix and co-teaches a creative writing course through the University of Gävle in Sweden in addition to her consulting practices.
\end{abstract}

The book serves as a terrific resource for both novice distance educators and as a reference for those who are more experienced. It lays out most of the things needed to teach online through coaching the readers to understand the current situation and pass onto next levels of sophistication in e-learning practices. Two critical things that are emphasized in the book are interaction as the core of learning, and collaboration among the distance education practitioners. The focus is not on developing Web pages, troubleshooting specific software or providing student support services. Rather, it focuses on the requirements for instruction and underlines where we might need to collaborate with others to create the best practice both for us and for our students.

Chapter 1 discusses the tools available for distance learning along with suggestions on how they may be used. Chapter 2 describes the distance population addressing different learning styles, attitudes and generational differences all of which might affect the way students enter the class, and work with the teacher and materials. Chapter 3 and 4 focus on instructional design and development with a particular emphasis on creating content, which is both interactive and in line with learning 
objectives. Chapter 5 provides ideas on managing the distance classroom with concise and thoughtful tips.

Chapter 6 provides clues on how to diagnose individual learners, work with their strengths and weaknesses, and motivate them through appropriate coaching techniques. Chapter 7 discusses the ways for creating effective learning communities at a distance. Finally, Chapter 8 examines distance learning as a collaborative enterprise, and reviews the challenges, potential and collaborative roles involved in distance learning.

The book can help professionals teaching at colleges or universities to adapt their teaching styles to a distance format. It can give clues on selecting and implementing low-cost and low-tech options effectively in case the practitioners do not have enough budget or access to high-tech platforms. It further tries to give clues on how to interact with students rather than simply talk about what we know. Finally, it provides instructors with step-by-step guidance while dealing with distance learning endeavors. In brief, teachers, college instructors, consultants, and decision makers in the field could make an effective use of the book as it involves a concise overview of effective and up-to-date information to run successful distance learning classes. 